\title{
O PROJETO DE GESTÃO AMBIENTAL E TERRITORIAL INDÍGENA (PROJETO GATI): A EXPERIÊNCIA NA TERRA INDÍGENA OCO'Y
}

\author{
Roberto dos Anjos Dias* \\ Universidade Estadual do Oeste do Paraná
}

Resumo: 0 trabalho tem por objetivo analisar a aplicação do Projeto Gestão Ambiental e Territorial Indígena - Projeto GATI (GEF INDíGENA/PNUD BRA09/G32) na Terra Indígena Oco'y. O Projeto é uma experiência piloto que foi aplicada em 32 terras indígenas nos 05 biomas brasileiros. Possui amplos objetivos que possuem a finalidade de consolidar as terras indígenas brasileiras como áreas essenciais para a conservação da biodiversidade. O Projeto GATI teve uma duração de dois anos, período em que diversas ações foram propostas e executadas na Terra Indígena Oco'y. Através de análises de documentos, entrevistas e trabalho de campo identificou-se que das ações previstas poucas foram executadas e de forma incipiente. Ademais, constatou-se que o Projeto apresentou pressupostos teóricos adequados e avanços na superação de burocracias e barreiras institucionais, entretanto sua aplicação não teve participação comunitária, suporte institucional bem como não houve continuidade das ações.

Palavras-chave: Avá-Guarani. Oco'y. Projeto GATI.

\section{THE INDIGENOUS ENVIRONMENTAL AND TERRITORIAL MANAGEMENT PROJECT (GATI PROJECT): THE EXPERIENCE ON OCO'Y INDIGENOUS LAND}

Abstract: The aim of this work was to understand the application of the Indigenous Environmental and Territorial Management Project - GATI Project (GEF INDÍGENA/PNUD BRA09/G32) at Oco'y Indigenous Land. The Project is a pilot experiment that was applied in 32 indigenous lands at 05 different Brazilian biomes. This project has broad objectives that aim to consolidate Brazilian indigenous lands as essential areas of biodiversity conservation. The GATI Project lasted two years, period in which several actions were proposed and implemented at Oco'y Indigenous Land. By the analysis of documents, interviews and fieldwork, it was identified that few of the planned actions were carried out in an incipient way. In addition, it was verified that the Project presented adequate theoretical presuppositions, advances in the overcoming of bureaucracies and institutional barriers; however, its application did not have community participation, institutional support as well as there was no continuity of actions.

Keywords: Avá-Guarani. Oco'y. GATI Project.

\section{EL PROYECTO DE GESTIÓN AMBIENTAL Y TERRITORIAL INDÍGENA (PROYECTO GATI): LA EXPERIENCIA EN LA TIERRA INDÍGENA OCO'Y}

Resumen: Este estudio tiene por objetivo hacer un análisis de la aplicación del proyecto Administración ambiental y territorial indígena - Proyecto GATI (GEF INDÍGENA/PNUD BRA09/G32) en la Tierra Indígena Oco'y, ubicada en la microrregión de Foz do Iguaçu, en la región Oeste del Paraná, en la ciudad de São Miguel Do Iguaçu. El proyecto es una experiencia piloto que fue aplicada en 32 tierras indígenas en los cinco biomas brasileños, entre los años de 2010 y 2016. Es un proyecto con grandes objetivos como la consolidación de las tierras indígenas brasileñas como áreas esenciales para la conservación de la biodiversidad. El Proyecto GATI ocurrió durante seis años, en los cuales diversas acciones fueron propuestas y ejecutadas en la Tierra Indígena Oco'y. Mediante de análisis de documentos, entrevistas y de pesquisa de campo, pudimos percibir que, de las acciones previstas, pocas fueron ejecutadas, siendo que lo que fue hecho, fue incipiente. Además, fue constatado que, aunque el proyecto tenga presentado supuestos teóricos adecuados y progresos en la superación de la burocracia y de las barreras institucionales, su aplicación no tuvo ninguna participación de la comunidad o apoyo de instituciones, así que no hubo continuidad de las acciones.

Palabras clave: Avá-Guarani. Oco'y. Proyecto GATI. 
Introdução

A partir da década de 1970, o movimento indígena passa a se articular em prol de seus direitos e encontra no apelo ambiental um forte aliado. Para Lima e Pozzobon (2005) a valorização dos critérios de sustentabilidade ecológica trouxe um valor positivo às chamadas comunidades tradicionais. Para o autor, estes grupos "incorporaram a marca ecológica às suas identidades políticas como estratégia para legitimar novas e antigas reivindicações sociais"(LIMA; POZZOBON, 2005, p. 45).

Com a absorção desse valor ecológico positivo pelos movimentos indígenas reforçou-se a característica de cuidado ambiental destes povos. E desde então, diversas políticas, programas e projetos articulam qualidade de vida com conservação ambiental.

Nesse contexto, o tema gestão territorial em terras indígenas vem se destacando na reflexão sobre as ações de desenvolvimento e superação de desafios das terras indígenas brasileiras demarcadas. Isto, pois, abarca a importância tradicional do território e seus recursos naturais para os povos indígenas, bem como articula e debate diversos outros temas voltados a manutenção ou condução da sustentabilidade das terras indígenas (INGLEZ DE SOUZA, 2012; REDE DE COOPERAÇÃO ALTERNATIVA, 2013).

A articulação é feita principalmente em torno de projetos de gestão territorial envolvendo setores representantes de diferentes áreas do conhecimento e com interesses muitas vezes conflituosos. Como, por exemplo, a questão ambiental representada pelo Ministério do Meio Ambiente (MMA) e ONGs ambientalistas, a questão educacional pelo Ministério da Educação e Cultura (MEC), os interesses indígenas representados pela Articulação dos Povos Indígenas do Brasil (APIB) e, muitas vezes, parceiros internacionais. A presença de tantos e diversificados gestores ${ }^{1}$ demonstra uma convergência de interesses que devem atuar de maneira unificada para que não sejam gastos esforços e recursos em atividades paralelas ou antagônicas.

Diante do exposto, nosso objetivo principal é compreender como se deu o processo de implantação do Projeto Gestão Ambiental e Territorial Indígena Projeto GATI (GEF INDÍGENA/PNUD BRA09/G32). 0 qual consiste em um projeto piloto que tem por objetivo 0 "uso sustentável e conservação dos recursos naturais e

1 A noção de gestores aqui presente quer dizer todo e qualquer indivíduo, órgão ou instituição responsável por ações diretas voltadas ao gerenciamento dos recursos materiais ou imateriais de um território indígena. a inclusão social dos povos indígenas, consolidando a contribuição das Terras Indígenas como áreas essenciais para conservação da diversidade biológica e cultural nos biomas florestais brasileiros" (PROJETO GATI, 2017).

O Projeto GATI foi aplicado em 32 terras indígenas brasileiras, sendo três destas na região Sul, entre elas a Terra Indígena Oco'y em São Miguel do Iguaçu, Estado do Paraná, área do presente estudo. A escolha da terra indígena do Oco'y justifica-se por ser a primeira terra indígena demarcada na margem do Rio Paraná, a qual possui seu processo de consolidação documentado, bem como por ser a única terra indígena Avá-Guarani selecionada para participar do Projeto GATI.

Realiza-se investigação sob uma perspectiva crítica, utilizando como forma de coleta de dados as visitas a campo e entrevistas semiestruturadas com os envolvidos no projeto. Bem como análise dos documentos resultados do trabalho da consultoria contratada para o projeto.

\section{Território e gestão territorial de terras indígenas}

O território é um conceito que pode ser definido como uma parcela do espaço apropriada, nos quais indivíduos, grupos ou instituições exercem o poder (RAFFESTIN, 1993), em outras palavras, o território é uma parcela do espaço produzida por uma rede de relações sociais, culturais, econômicas e políticas (CANDIOTTO, 2004). É historicamente produzido e reproduzido. Segundo Saquet $(2015$, p.45), "O território é produto das relações sociedade-natureza e condição para a reprodução social [e] os territórios são produzidos espaço-temporalmente pelo exercício do poder por determinado grupo ou classe social e por suas respectivas territorialidades cotidianas".

Como foi dito, é no território que se desenrolam as tramas políticas, culturais, econômicas, entre outras. E essas tramas, por sua vez, destroem, rearranjam e geram novos territórios. Em vista disso, compreende-se que o território é categoria relevante para planejamentos de gestão e desenvolvimento, pois a nosso ver, é na escala territorial que podem ser identificados os atores e processos que o modificam.

Diante dessas características, o território se torna adequado para pensar ações com base em conhecimentos diversificados e para a compreensão das relações de poder que articulam ou competem em um espaço delimitado, principalmente aliado ao recorte para terras indígenas, que se constituem em territórios onde perpassam relações de poder, que são culturais, políticas, 
organizacional e institucional, muitas vezes diversas, porém, visando à conservação da biodiversidade e dos aspectos culturais ali presentes.

Também, como afirma Guimarães, no início do século XXI a abordagem territorial foi considerada uma inovação para as políticas públicas. Segundo o autor:

O território é a unidade que melhor dimensiona os laços de proximidade entre pessoas, grupos sociais e instituições que podem ser mobilizadas e convertidas em um trunfo crucial para o estabelecimento de iniciativas voltadas para o desenvolvimento [...] Mas a abordagem territorial não significa apenas uma escala dos processos de desenvolvimento a ser considerada, ela implica também um determinado método para favorecê-los. Nela, o desenvolvimento não é decorrência da ação verticalizada do poder público, mas sim da criação de condições para que os agentes locais se mobilizem em torno de uma visão de futuro, de um diagnóstico de suas potencialidades e constrangimentos, e dos meios para perseguir um projeto próprio de desenvolvimento sustentável. Este é o principal legado da política pública de desenvolvimento territorial, a capacidade desenvolvida no coletivo de pensar, compreender e agir coordenadamente (GUIMARÃES, M. 2014, p. 123).

A nosso ver a abordagem territorial possibilita a superação da ideia de intervenção, isto é, da ação de seres exteriores que levam produtos de qualidade superior e que não podem ser criadas pela realidade local (LONG, 2007). Neste sentido, a abordagem territorial pressupõe o reconhecimento do Estado de que há a possibilidade de desenvolver determinado território a partir das potencialidades endógenas e da capacidade dos atores locais de serem protagonistas do desenvolvimento de seu território.

Nesse sentido, Saquet e Sposito (2008) afirmam que as iniciativas voltadas para o desenvolvimento territorial devem considerar os seguintes aspectos:

- A articulação de classes e a constituição de redes e tramas locais e extra locais, que significam relações de poder, efetivadas em cada lugar e entre os lugares, em virtude de suas desigualdades, diferenças e especificidades.

- O caráter (i)material, conciliando-se os fatores e elementos culturais, políticos, econômicos e naturais, em unidade.

- A produção de mercadorias (ou excedentes), a recuperação e a preservação da natureza exterior ao homem.

- A valorização das pequenas e médias iniciativas produtivas.

- A valorização dos saberes locais e das identidades.

- A consideração do processo histórico e do patrimônio de cada lugar.

- A produção ecológica de alimentos.

- A organização política local, com vistas à conquista de autonomia.

- A diminuição das injustiças e das desigualdades sociais, dentre outros (SAQUET; SPOSITO, 2008, p. 28).

Sendo assim, adotar a abordagem territorial como categoria de planejamento de políticas públicas é reconhecer que há um espaço delimitado onde determinado grupo manifesta poder, detém recursos que estão no centro de disputas e onde grupos buscam realizar suas vidas. Esta diferente leitura da realidade por parte do Estado, desperta o território como um recorte potencial para o desenvolvimento e, igualmente, para a necessidade de novos métodos que levem em conta os diversos componentes territoriais existentes, sejam eles econômicos, culturais, políticos ou ambientais.

Além do poder do Estado que reconhece os direitos indígenas sobre o território, os índios têm legitimado mais do que sua apropriação (que independe do Estado e é reconhecida nas legislações indigenistas), o seu domínio do território, podendo restringir o acesso às terras, organizar-se de forma tradicional e utilizar os recursos naturais presentes no território conforme suas necessidades, como propósito principal a sustentabilidade da comunidade e não exigências de mercado. Bem como estes povos podem acessar políticas públicas diferenciadas ou comuns a toda população, o que torna os territórios indígenas um ambiente diferenciado para a realização de propostas de desenvolvimento sustentável.

Garcia (2014 p. 50) destaca que o fim do monopólio de ação governamental e o avanço das demarcações "[...] levou à percepção da necessidade de as organizações indígenas adquirirem novas competências e habilidades para gerir as terras indígenas reconhecidas". Diante do novo território os indígenas passam a lidar com novas variáveis: Como lidar com uma população que tende a crescer em um espaço finito e com recursos limitados; 0 que fazer quando a terra demarcada é insuficiente? Como proteger a integridade e os recursos naturais da terra indígena? Como dar conta dos novos desejos de consumo e proteger as tradições indígenas? (INGLEZ DE SOUZA, 2012, p. 32).

A partir da década de 1990, impulsionados pela Conferência das Nações Unidas sobre o Meio 
Ambiente e Desenvolvimento, a ECO 92, realizada no Rio de Janeiro, movimentos sociais e ambientalistas reivindicam a criação de meios de proteção às florestas e aos povos que as habitam (GUIMARÃES, 2014). Dessa forma o atributo conservacionista das terras indígenas foi se consolidando (BAVARESCO e MENEZES, 2014). Desde então começou a surgir diversos programas e fontes de financiamento, tanto governamentais, não governamentais e de cooperação internacional voltadas para projetos indígenas (INGLEZ DE SOUZA e ALMEIDA, 2012).

Para Little (2006), existem duas agendas políticas que atuam e demandam instrumentos técnicos para a gestão de terras indígenas, que seriam "[...] a agenda de direitos étnicos e territoriais dos povos indígenas e a agenda ambientalista da sustentabilidade" (LITTLE, 2006, p.16). Para conciliar estes objetivos é utilizada a noção de "Gestão Territorial das Terras Indígenas", a qual não possui uma definição rígida, mas se configura num mote (INGLEZ DE SOUZA e ALMEIDA, 2012, p. 39) ou uma "lona de proteção" sob a qual diversos assuntos são debatidos em prol da sustentabilidade das terras indígenas (GTZ, 2009, p. 19).

Através da utilização da "Gestão Territorial das Terras Indígenas" delimita-se um campo de atuação e se estabelece um norte de atuação, e assim, tem-se um conjunto de conceitos e técnicas que podem ser direcionadas ao atendimento das demandas das duas agendas políticas supracitadas.

Entre 1999 e 2004, também foram realizados os Projetos Demonstrativos dos Povos Indígenas (PDPI) voltados à qualidade de vida e conservação de recursos naturais de povos indígenas na Amazônia. Embora tenha demorado um pouco para as organizações indígenas se adequarem, mais de 270 projetos foram enviados e mais de 70 aprovados $^{2}$ (BAVARESCO e MENEZES, 2014; GUIMARÃES, 2014). Outros programas como Carteira Indígena e o GEF Indígena, que veio a se tornar o Projeto GATI, sempre mais amplos e complexos, mostraram o amadurecimento do diálogo entre Estado, povos indígenas e redes de financiamento.

\section{Metodologia}

Para aferir sobre as ações do Projeto GATI, foram feitos trabalhos de campo na comunidade no mês de abril de 2016, nos quais foram realizadas entrevistas

2 PDPI: um caso especial. Disponível em:<http://pib.socioambiental.org/pt/c/ politicas-indigenistas/o-estado/pdpi:-um-caso-especia>. Acesso em: set.2016 semiestruturadas gravadas e conversas com participantes indígenas e não indígenas de diferentes etapas do Projeto GATI. Os três entrevistados em campo tiveram seus nomes alterados em atendimento às normas item Resolução 466/12 do Conselho Nacional de Saúde. Também fizeram parte do trabalho registros fotográficos realizados pelo próprio autor.

Foram realizadas, igualmente, entrevistas semiestruturadas com a consultoria do projeto e os representantes da Associação dos Produtores de Agricultura e Pecuária Orgânica de São Miguel do Iguaçu - APROSMI, instituição parceira da implantação do projeto.

No total foram realizadas cinco entrevistas, sendo três realizadas em campo e duas por e-mail. Além destas foram realizados diálogos informais sobre o projeto com mais quatro pessoas. Estes indivíduos foram escolhidos devido a sua participação direta em diferentes etapas do Projeto.

Realiza-se uma análise comparativa das ações encontradas em campo somadas às entrevistas mencionadas anteriormente, com os protagonistas do projeto a nível local. Para isto, igualmente, utilizase informações contidas nos documentos "Produto 02: relatório de acompanhamento da formação e intercâmbios e outras capacitações envolvendo as Áreas de Referência; avaliação dos resultados e apresentação dos desdobramentos e encaminhamentos necessários" (VILLANUEVA, 2014a), "Produto 3: Documento contendo: (1) relatório da execução dos projetos elaborados no âmbito do projeto GATI; (2) necessidade de ajustes e/ ou atividades complementares tais como contratações de consultorias, capacitações, materiais/equipamentos específicos" (VILLANUEVA, 2014b), "Produto 04: Documento contendo relatório de acompanhamento das oficinas de etnomapeamento (cartografia social)" (VILLANUEVA, 2015a) e "Produto 06: Sistematização, síntese e avaliação dos resultados da consultoria e das ações do Projeto GATI no Núcleo Regional Mata Atlântica Sul: Terras Indígenas Ibirama - SC, Mangueirinha e AvaGuarani de Oco'y - PR" (VILLANUEVA, 2015b).

Por fim, partindo do documento Síntese da reunião de instalação do Conselho Regional do Núcleo Regional Sul do Projeto GATI (VILLANUEVA, 2012a), elabora-se uma tabela que sintetiza todas as ações previstas no início do Projeto no ano de 2012 e em comparação com as ações realizadas no fim do Projeto no ano de 2014.

De acordo com o informado por Villanueva por e-mail, o seu contrato iniciou em 27\03\2014 com vigência 
até $14 \backslash 10 \backslash 2014$; antes do início, ela prestou apoio ao Projeto como colaboradora. Ao término do contrato, foram entregues 06 produtos da consultoria, os quais subsidiaram este trabalho. Tais documentos foram disponibilizados através de solicitação ao Sistema Eletrônico de Serviço de Informação ao Cidadão (protocolo 08850001174201666) e através de troca de e-mails com a consultora.

Investigação sobre as atividades propostas e realizadas pelo GATI no Oco'y

O GATI iniciou suas atividades a partir de uma consulta regional, realizada em Florianópolis, no estado de Santa Catarina, entre os dias 24 e 26 de outubro de 2012. Nesta etapa, estavam presentes representantes das terras indígenas de Ibirama, de Santa Catarina, e Mangueirinha e Oco’y, no Paraná. Segundo o informado no documento final, "A programação da reunião visava integrar as ações governamentais nas três áreas de referência para, a partir dessa integração, ser construído o plano de trabalho do Projeto GATI para cada uma das áreas" (VILLANUEVA, 2012a, p. 02). Para isto, contou com participação de lideranças indígenas, servidores da FUNAI, representantes de órgãos parceiros e do Programa das Nações Unidas para o Desenvolvimento. Foram três dias de debates, com o objetivo de organizar a gestão do Projeto, resultando na construção do Conselho Regional Deliberativo do Núcleo Regional Sul do Projeto GATI. E, por fim, organizados em grupos por áreas de referência, lideranças indígenas e representantes dos órgãos debateram sobre os Planos de Ação que deveriam ser estabelecidos em cada uma das TIs (VILLANUEVA, 2012a).

Naquela reunião compareceram o cacique Daniel Maraca Lopes, o professor Luiz Mbaraka Miri Martines e a professora Delmira de Almeida Peres, como representantes da TI Oco'y. Porém, estes tiveram problemas com o voo e chegaram na noite do dia 24 , perdendo o dia das discussões.

Segundo informado em campo, que na interpretação dos representantes da TI Oco'y nesta reunião, os indígenas teriam participado apenas para dar "ok" nas atividades, pois tudo já estava montado. Portanto, sem uma participação significante no planejamento e estruturação do Projeto GATI em sua aldeia.

Na formulação das atividades em Santa Catarina, você participou, teve opinião, teve voz ou só apresentaram para você?

Daquela vez que fui já tinha acontecido algumas vezes. Quando nós chegamos já tinha começado, então foi muito pouco que participei. Aqui inclusive quando teve a reunião com a Rosa e o pessoal do projeto eu não participei

As atividades práticas foram iniciadas na comunidade no fim de 2013, com ações focadas na necessidade de otimização do território indígena para a produção de alimentos, principalmente frutas e hortaliças. Foram realizadas diversas ações combinadas que compõem dois microprojetos: "Apoio à implantação de pomar agroflorestal" e "Agrofloresta para segurança alimentar e recuperação de áreas degradadas" (GESTÂO AMBIENTAL E TERRITORIAL DE TERRAS INDÍGENAS, 2016).

Segundo o relatório (VILLANUEVA, 2014a) entregue pela consultora do Projeto GATI, no âmbito do intercâmbio houve a participação de um indígena e o representante da Associação dos Produtores e Pecuária Orgânica de São Miguel do Iguaçu, Adelar de Oliveira, no VII Congresso Brasileiro de Agroecologia em novembro de 2013. E na etapa da capacitação foram feitas visitas em propriedades agroecológicas do entorno, com objetivo de sensibilização ao tema, bem como foram desenvolvidas três oficinas voltadas a implantação de agrofloresta e hortas de mandala.

Para a realização das oficinas, o projeto contou com o transporte feito pela Prefeitura Municipal de São Miguel do Iguaçu e durante o restante das atividades da implantação do Projeto houve parceria de assistência técnica de funcionários da APROSMI, sendo realizada no fim de 2013, por Adelar de Oliveira; no primeiro semestre de 2014; e por Luciano Acker, entre junho e julho de 2014, foi realizado a contratação de Renan Campos através da modalidade de pequenos contratos por Termo de Referência (VILLANUEVA, 2015)

Após as observações em campo foi possível constatar que os dois microprojetos não possuem profundas diferenças. As ações de "agrofloresta" receberam títulos diferenciados devido a seu local de implantação ou objetivos, entretanto, as ações foram apenas o plantio de mudas selecionadas em diferentes áreas da comunidade. Como pode ser visto na figura abaixo. 


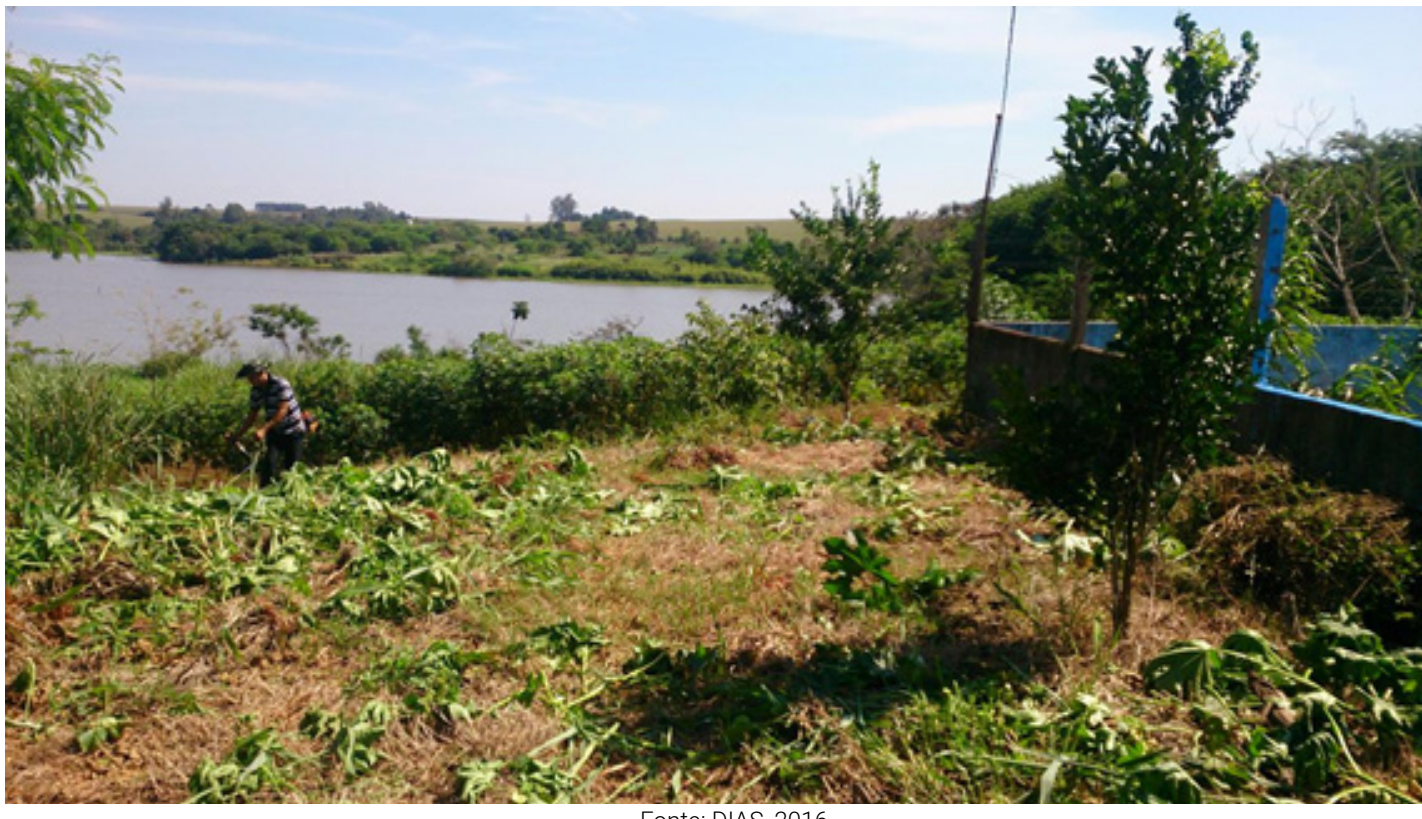

Fonte: DIAS, 2016.

A constituição de uma agrofloresta, também chamada de sistema agroflorestal (SAF), não se constitui apenas do plantio de mudas de interesse da comunidade, mas sim o estabelecimento de um sistema controlado que simule as etapas naturais de formação de uma floresta, recompondo áreas degradadas e, futuramente, fornecendo e produzindo para alimentação e/ou comércio.

Como afirmam Candiotto, Carrijo e Oliveira (2008):

Quando manejamos uma floresta para obtermos alguma espécie de benefício sem degradá-la, estamos praticando uma atividade chamada de extrativismo, muito desenvolvida pelos índios. Quando iniciamos uma recuperação de um solo degradado e abandonado, tendo em vista a sucessão natural citada acima, até chegar a características próximas de uma floresta, porém implantando espécies de interesse agrícola juntamente com espécies nativas, estamos desenvolvendo uma atividade chamada agroflorestal. (CANDIOTTO, CARRIJO e OLIVEIRA, 2008, p. 226; grifos do original).

Dessa forma, é possível perceber que as atividades voltadas à constituição de uma agrofloresta são muito mais complexas do que o plantio de mudas em áreas fragilizadas. A construção de um sistema agroflorestal passa pela recuperação de diferentes estágios de sucessão encontrados em uma floresta. Para isso, é necessária a capacitação sobre formação e estrutura de cada uma destas etapas, bem como o conhecimento do manejo das espécies selecionadas.
A outra atividade é a horta de mandala que é uma forma de produzir de base agroecológica que, assim como a agroecologia e os sistemas agroflorestais e outras formas de "eco-agricultura", são variantes do que Ehlers (1996) chama de movimentos rebeldes, "[...] alguns movimentos contrários à adubação química que valorizavam o uso da matéria orgânica e de outras práticas culturais favoráveis aos processos biológicos" (EHLERS, 1996, p. 49).

Sobre as vantagens da construção das hortas em mandala, Sergio afirma:

Qual a vantagem que você viu na horta de mandala, diferente do cultivo comum?

A horta mandala, pelo que eu vejo, ela atrai muita curiosidade. 0 pessoal de fora que vem pergunta 'onde que vocês fizeram a horta, posso ir lá visitar?' [...] A vantagem é que através dessa horta, ali na frente ele [o vizinho] encheu de cebola. Porque cebola aqui você planta, é só fazer irrigação sempre, que vai bem. A vantagem pelo que eu vejo... Tem um cara que trabalha na SEASA em Foz que vem sempre comprar cebola. Por exemplo, daqui ele pega um pouco, de lá já completa uma caixa e assim vai. Aí que a pessoa percebe que se aumentar ou se fazer mais algum projeto que aumente a parte da verdura, essas coisas, é o lucro que dá né. Através dessa horta... Porque antes ninguém se interessava, às vezes tinha um pedacinho plantado só pra consumo no dia a dia.

Sergio também informa que, atualmente, não está utilizando com intensidade a sua horta devido a estação de verão e ele não poder irrigar conforme é preciso. 
Pretende voltar a utilizá-la no inverno.

Como é possível perceber na fala de Maria e Sergio, as ações do GATI de maneira geral não envolviam os indivíduos específicos da comunidade. Na realidade, foram atividades endereçadas a toda a comunidade sem estabelecer um compromisso e sem esclarecer as responsabilidades individuais.

Como afirma Maria:

Você participou da reunião do GATI?

Não lembro bem, mas estive com a Rosa umas duas ou três vezes.

Eu acho assim... Esses projetos, eu falo bem a verdade sabe, então bem no começo, quando teve o início desse projeto, não quando iam implantar, quando iam começar a organizar, aí foi eu e o Luiz, meu marido, na outra foi outra [pessoa] e numa outra [reunião] eu e o Luiz de novo, e em outra [reunião] foi outra [pessoa]. Aí a gente fica assim "será que sou responsável, será que não sou". Então eu acho que esses projetos, o dia que acontecer aqui de novo, tem que pegar uma pessoa e se responsabilizar, "esse trabalho é seu", eu acho que tinha que ser feito assim. Foi trazido umas plantinhas, aí esse professor era responsável, era só ele e aí veio férias. A gente pensou que iam limpar, iam regar, iam molhar...

Então eu acredito que é falta de organização, falta de uma pessoa, por exemplo, pegar do início até o fim. Então assim, por exemplo, vai acontecer um curso da área desse projeto ou evento, aí vai uma pessoa, vai acontecer outra coisa, vai outra pessoa.

Percepção semelhante é constatada na fala de Sergio:

Eu aprendi também que tem que ver uma família que tem interesse mesmo, porque, se não, não adianta você fazer um trabalho certinho e bonitinho e de repente [acabou]... porque eu não tenho como ir cuidar da horta dele né, então ele que é responsável. Que nem, aqui ninguém pode vir mexer na minha horta por que eu que sou dono né, então tem que cuidar pra que a pessoa aproveita bem. Então não adianta fazer um trabalho certinho e a pessoa abandonar, então é um trabalho perdido que a gente faz com cuidado, certinho, ensina e de repente você vê que não vai valer a pena que o que você fez.

E na implantação do GATI, você viu mais alguma coisa que não funcionou, o que você achava que podia ser diferente?

Acho que o projeto foi bem feito, só que a família que se incluiu, faltou um pouco de interesse né. Foi próprio da família mesmo. Porque o projeto mesmo, cada projeto tem intenção que melhore a vida da comunidade, do morador. Só que muitas vezes...por exemplo se eu não tenho interesse, tenho que deixar para outro que tem. Não adianta pegar para largar tudo.

Ambos se mostram descontentes pelo abandono por parte de alguns indígenas que participaram da atividade e abandonaram ou se mudaram não dando continuidade no Projeto. Também destacados como falha do Projeto, a sua implementação em períodos curtos sem alguma forma de continuidade e a demora do contato entre os indígenas e os proponentes.

Como informa Sergio:

E por parte da FUNAl, do poder público, o que você acha que foi problema? Apenas ter parado, faltou mais assistência técnica, contato com a Rosa?

Acho que faltou a continuidade, né. Contato também, né. A rosa morava em são Paulo, eu acho, então não tem condições de vir e voltar. Nessa parte a gente tinha dificuldade de contato, as vezes a gente precisa de alguma coisa e não consegue entrar em contato, "não, só mês que vem ou daqui três meses", então a gente espera, vai esperando, então ela vem para resolver as coisas.

Percebe-se que faltou engajamento da comunidade em torno do projeto. A participação dos indígenas foi mínima e não houve protagonismo indígena nas ações realizadas. Entende-se que a falta de internalização das ações e objetivos do Projeto foi resultado de uma ação vertical e pouco dialogada.

Como levantado em campo, o Projeto GATI foi finalizado após as atividades de instalação das hortas de mandala, em 2014. A última ação relativa ao Projeto foi a abertura do edital Programa de Pequenos Projetos de Gestão Ambiental e Territorial Indígena (PPP GATI), realizado em parceria com o Instituto Sociedade População e Natureza (ISPN), cujo objetivo seria apoiar ações de conservação da biodiversidade e melhoria da qualidade de vida dos povos indígenas. Entretanto, no resultado final nenhum trabalho foi proposto para a comunidade do Oco'y. Segundo o entrevistado, os indígenas e envolvidos contavam com esse edital para dar continuidade ao Projeto, entretanto a falta de servidores foi apontada como motivo em dar apoio técnico e montar o projeto para a comunidade (VILLANUEVA, 2015a). Este fato desperta para a problemática dos mecanismos institucionais de financiamento e o acesso a estes por parte dos povos indígenas, nem sempre qualificados a atuar no sistema não-indígena.

Segundo informado por Sergio, a última atividade 
realizada foi a "Agrofloresta e Horta de Mandala" (FIGURA 02), que foi finalizada no segundo semestre de 2014. Segundo o entrevistado, este foi contatado pela APROSMI, que explicou do que se tratava o projeto, como pode ser visto a seguir:

\section{Como você conheceu o GATI?}

Através da APROSMI, que estava previsto o projeto aqui dentro, então em parceria, né, com a FUNAI. 0 projeto GATI é da FUNAI né!? Então Adelar falou assim pra mim, se você se interessar tem o Projeto GATI da FUNAI. Daí eu falei assim, dá sim pra mim. Daí ele começou a explicar mais o que era o projeto, aí eu comecei.
Ele que te explicou? O que ele disse?

Ele explicou que o Projeto do GATI é da FUNAI. Aquele projeto do GATI que eu peguei pra Agrofloresta e Horta Mandala... é.. foi durante 08 meses que era o projeto, né.. A proposta para mim assim era durante 08 meses eu começava a trabalhar com os projetos e começava a orientar as famílias que vai, digamos assim...

Eu cheguei a conversar com os moradores que tivessem interesse de participar. Fizeram a proposta assim, vai ter 8 mil reais nesse projeto... como eu não vou conseguir fazer isso sozinho entrou dois, eu e mais outro, que trabalhou pra mim que mora lá do outro lado. Daí durante os primeiros quatro meses eu recebi dois mil, tanto o outro recebeu dois mil.

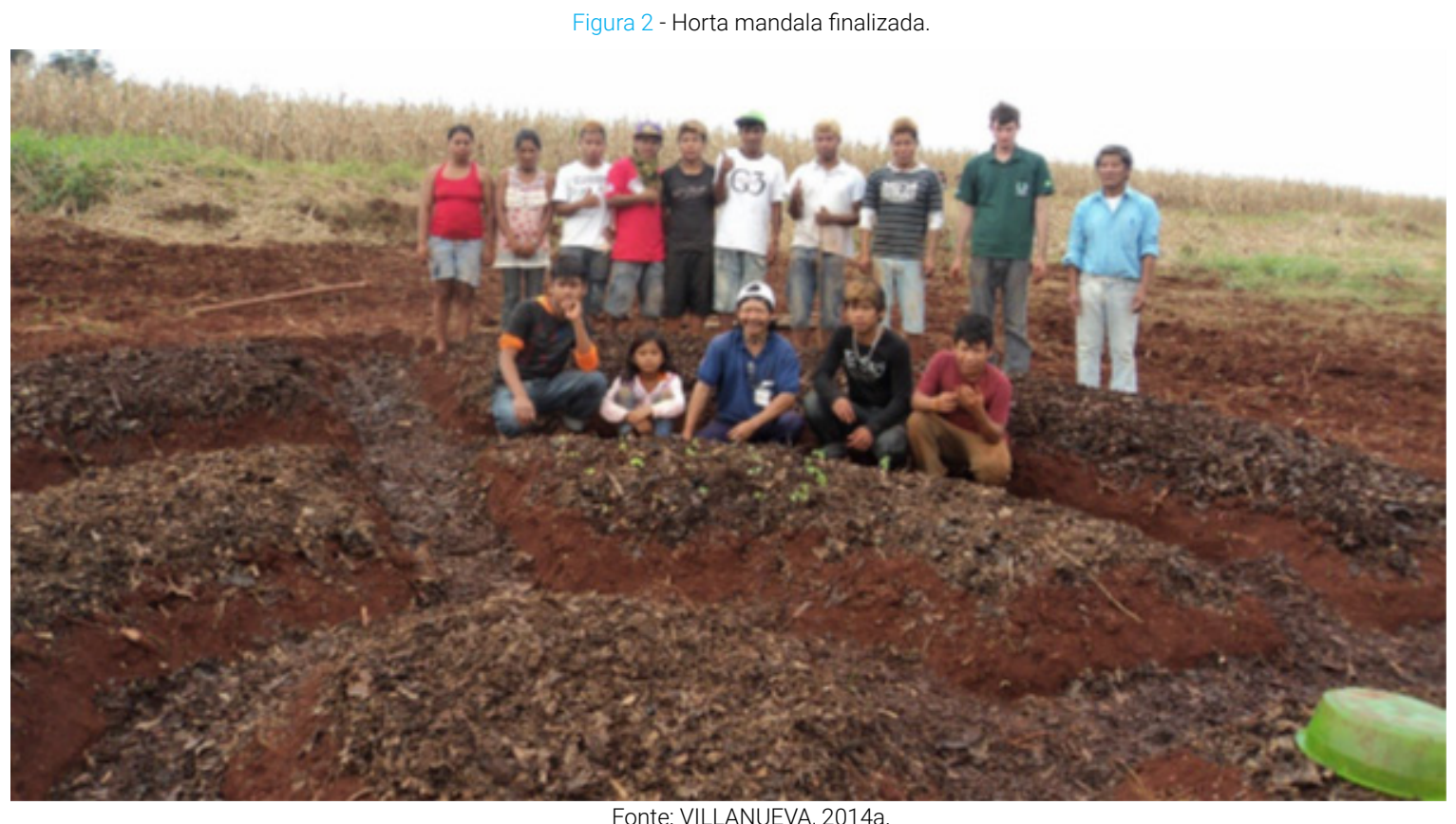

Segundo o entrevistado este recebeu um valor total de 8 mil reais, que foi pago em duas parcelas a cada 4 meses. Devido a quantidade de trabalho, ele necessitou dividir as tarefas com Carlos e a quantia recebida. Dessa forma, ambos receberam dois mil reais a cada quatro meses, o que dá 500 reais mensais para prestar assistência técnica rural na comunidade.

Sergio informa que no fim de 2014 se conseguiu mais remuneração para outras famílias indígenas participarem do projeto como uma forma de continuidade. Estas, por sua vez, também dividiram a verba para agregar mais famílias.

Ao que tudo indica as contratações foram realizadas através do chamado "microprojetos indígenas" que constituíram-se de pequenos subsídios de até 4 mil reais para indígenas que desenvolviam iniciativas práticas na comunidade voltadas a gestão ambiental e conservação da biodiversidade (VILLANUEVA, 2014b). Este mecanismo de financiamento, juntamente com "Contratações simplificadas através de Termos de Referência - TdR", "Concessão de diárias e auxílio para deslocamentos para colaboradores eventuais" e "Apoio a pequenos projetos ", foram formas de superar os entraves burocráticos, operativos e financeiros das coordenações da FUNAI que não são capazes de atender as demandas específicas que surgiam durante a execução do Projeto GATI.

É importante destacar que a Coordenação Técnica Local responsável pelo atendimento a TI Oco'y localizase há mais de 100 quilômetros da aldeia e conta com apenas 02 funcionários para 0 atendimento de 18 aldeias dispersas por todo o oeste do Paraná. Além de uma infraestrutura irrisória, contando com apenas 01 veículo em funcionamento, desta maneira o trabalho da 
Figura 3 - Escritório praticamente abandonado da FUNAI dentro da TI Oco'y.

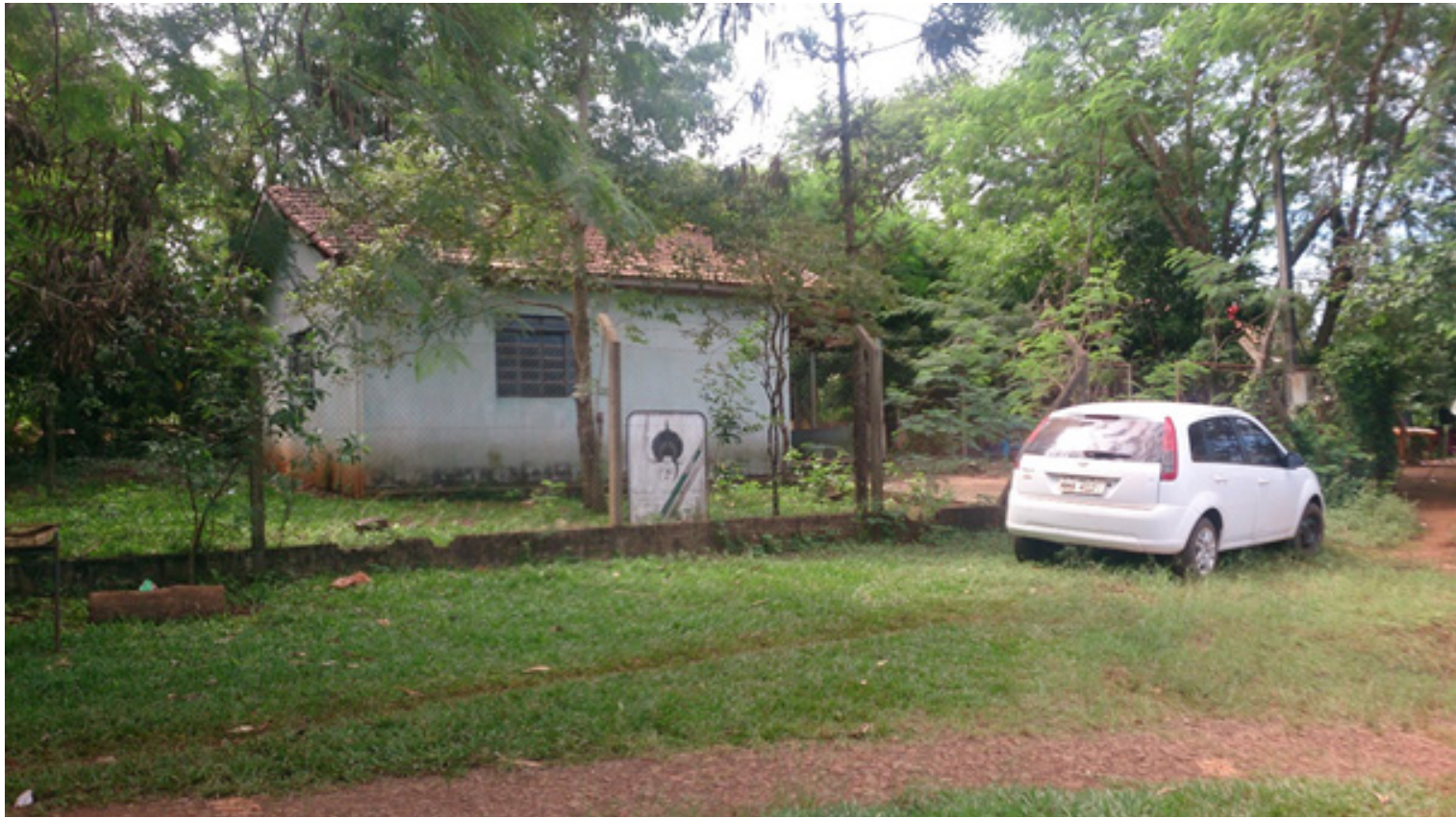

Fonte: DIAS, 2016.

CTL consiste basicamente em atender a documentação básica dos indígenas, não tendo competência técnica na área agrícola ou de gestão de projetos. Há também um segundo posto de atendimento da FUNAI dentro da TI, porém encontra-se sem infraestrutura e praticamente abandonado, conforme é possível ver na figura a seguir.

De acordo com o exposto no Produto 6 (VILLANUEVA, 2015b), mais 05 famílias foram apoiadas através de 03 microprojetos, entre novembro de 2014 e fevereiro de 2015. Além disso, o documento informa que o cacique procurou a consultora em busca de mais projetos, esta, por sua vez, repassou a solicitação para a coordenação do Projeto e para a FUNAI.

Sobre as expectativas em relação ao Projeto, afirma:

O que você espera para os próximos anos, com a conversa de hoje? Acha que tem chance de voltar, ou vai ficar nesses projetos de 04 ou 08 meses? Qual sua expectativa para o GATI?

A gente sempre espera mais novidade sobre projeto. A gente quer ver mais projeto. Não é projeto só pra horta mandala, só pomar. Quer mais projeto pra gente evoluir cada vez mais. Através do projeto eu aprendi muitas coisas que nunca pensei de aprender. A experiência que tenho é através de projeto, então a gente trabalha através do projeto, a gente aprende, a gente ensina, a gente faz palestra. Então esse projeto também traz experiências pra nós. [...] A expectativa pra mim é que seja feita um projeto em parceria com a APROSMI, pra aproveitar o espaço que temos através de projeto.
É importante destacar que além destas etapas realizadas, no documento Síntese da reunião de instalação do Conselho Regional do Núcleo Regional Sul do Projeto GATI" (VILLANUEVA, 2012) havia os seguintes objetivos a serem realizados: 1) Etnomapeamento com enfoque em identificação da biodiversidade de valor cultural e de áreas de invasão; 2) Cercamento das áreas de invasão; Formação e capacitação de jovens indígenas para atuação como Agentes Ambientais; 3) Revitalização de trilhas e construção de centro de lazer e visitação; 4) Fortalecimento de Redes de experiências com outras aldeias guarani, inclusive no Paraguai, com enfoque na agrobiodiversidade guarani; 5) Criação de um banco de sementes tradicionais guarani; 6) Pomar na área da escola e quintais agroflorestais; 7) Diagnóstico da agrobiodiversidade local (VILLANUEVA, 2012).

Através da pesquisa de campo e investigação dos documentos foram sistematizados na tabela abaixo as ações realizadas e não realizadas: 
Tabela 1

\begin{tabular}{|c|c|c|}
\hline Atividades propostas & $\begin{array}{l}\text { Atividades } \\
\text { previstas }\end{array}$ & Informações complementares \\
\hline $\begin{array}{l}\text { Etnomapeamento com } \\
\text { enfoque em identificação da } \\
\text { biodiversidade de valor } \\
\text { cultural e de áreas de invasão }\end{array}$ & Não & $\begin{array}{l}\text { O etnomapeamento só foi realizado na TI Ibirama, } \\
\text { por ocasião de um pesquisador que já pretendia } \\
\text { realizar trabalho semelhante. A não realização da } \\
\text { atividade nas terras indigenas do Paraná foi } \\
\text { justificada "por absoluta falta de disponibilidade } \\
\text { dos poucos pesquisadores desta linha que atuam } \\
\text { no estado do Paraná" (VILLANUEVA, 2015a, p. } \\
\text { 03). }\end{array}$ \\
\hline $\begin{array}{l}\text { Cercamento das áreas de } \\
\text { invasão }\end{array}$ & Não & $\begin{array}{l}\text { Apenas foram realizados plantios de mudas entre } \\
\text { as propriedades particulares e a Terra Indigena, } \\
\text { porém, em função do uso de agrotóxicos pelos } \\
\text { vizinhos quase a totalidade de mudas plantadas } \\
\text { foram perdidas. }\end{array}$ \\
\hline $\begin{array}{l}\text { Formação e capacitação de } \\
\text { jovens indigenas para atuação } \\
\text { como Agentes Ambientais }\end{array}$ & Insati & $\begin{array}{l}\text { As ações realizadas na comunidade contemplaram } \\
\text { (in)formações incipientes ou pontuais abertas a } \\
\text { toda a comunidade, sendo apenas o Sergio e Carlos } \\
\text { como participantes mais assíduos e que } \\
\text { desempenharam papeis práticos de implantação e } \\
\text { tutoria. }\end{array}$ \\
\hline $\begin{array}{l}\text { Revitalização de trilhas e } \\
\text { construção de centro de lazer } \\
\text { e visitação }\end{array}$ & Não & $\begin{array}{l}\text { Não houve nenhuma atividade que pode ser } \\
\text { identificada que contemplasse de alguma forma } \\
\text { esse objetivo. Bem como não consta nada no } \\
\text { documento final (VILLANUEVA, 2015b) } \\
\text { entregue pela consultora. }\end{array}$ \\
\hline $\begin{array}{l}\text { Fortalecimento de Redes de } \\
\text { experiências com outras } \\
\text { aldeias guarani, inclusive no } \\
\text { Paraguai, com enfoque na } \\
\text { agrobiodiversidade Guarani. }\end{array}$ & Insat: & $\begin{array}{l}\text { Foram realizadas visitas a propriedades de não } \\
\text { indigenas que produzem de forma agroecológica } \\
\text { na região e participação no VIII Congresso } \\
\text { Brasileiro de Agroecologia }\end{array}$ \\
\hline $\begin{array}{l}\text { Criação de um } \begin{array}{r}\text { banco de } \\
\text { sementes }\end{array} \text { tradicionais } \\
\text { Guarani. }\end{array}$ & Não & $\begin{array}{l}\text { Relativo a este objetivo apenas foram encontradas } \\
\text { algumas propostas de participação de viagens para } \\
\text { intercâmbio e troca de sementes e recursos para } \\
\text { aquisição de sementes (VILLANUEVA, 2014b; } \\
\text { 2015a) }\end{array}$ \\
\hline $\begin{array}{l}\text { Pomar na área da escola e } \\
\text { quintais agroflorestais }\end{array}$ & Insatisfatório & $\begin{array}{l}\text { Como já explanado anteriormente, foram } \\
\text { realizados atividades práticas Quintais } \\
\text { agroflorestais e Horta Mandala, porém o professor } \\
\text { indigena responsável se mudou para outro } \\
\text { município e não deixou outra pessoa para dar } \\
\text { continuidade nos trabalhos. As mudas plantadas } \\
\text { foram afetadas por agrotóxicos e boa parte se } \\
\text { perdeu. }\end{array}$ \\
\hline $\begin{array}{l}\text { Diagnóstico da } \\
\text { agrobiodiversidade local }\end{array}$ & Não & $\begin{array}{l}\text { Esta etapa constituir-se-ia de um trabalho } \\
\text { necessariamente fruto de alguma forma de } \\
\text { levantamento de dados, como foi visto } \\
\text { anteriormente, esta etapa também não ocorreu. }\end{array}$ \\
\hline
\end{tabular}

Percebe-se que o Projeto realizado trouxe algumas contribuições pontuais para algumas famílias e indivíduos, como o recurso, as experiências e o aprendizado. Outra contribuição importante foi a criação de mecanismos operacionais que superam burocracias contratuais, facilitando o financiamento de indivíduos e instituições parceiras e que suprem a falta de apoio da FUNAI, gerada pela precarização que vem ocorrendo ao 
longo dos anos.

Por outro lado, as ações foram significativamente desconexas. Faltou diálogo e protagonismo da comunidade na tomada de decisões e implantação das atividades. Nesse sentido, acredita-se que não cabe criticar a passividade dos atores locais, uma vez que foram desde a primeira etapa colocados em uma posição passiva. Embora as ações do Projeto GATI estivessem adequadas no campo do discurso agroecológico e social, as ações foram intervencionistas e pontuais, o que impossibilitou a mobilização da comunidade para dar continuidade no projeto.

\section{Considerações finais}

A gestão territorial de terras indígenas é um conceito que vem ganhando destaque nos últimos anos como estratégia de ação para a conservação ambiental, desenvolvimento sustentável e proteção territorial das terras indígenas. Seu uso foi institucionalizado através da Política Nacional de Gestão Ambiental e Territorial de Terras Indígenas. Esta política marca uma nova etapa de diálogo entre Estado e povos indígenas, bem como estabelece o território como critério para ação institucional, reconhecendo ao mesmo tempo a relação entre o povo indígena e seu território.

Nesse sentido, o Projeto GATI atua como um projeto piloto de implantação de ações de gestão territorial em terras indígenas. Sua experiência foi estabelecida em diversos biomas brasileiros, pois possui como objetivo constituir uma rede de experiências que servirão de modelos de gestão ambiental e territorial, garantindo a conservação da biodiversidade e dos recursos naturais. Parte-se também do princípio da gestão desses projetos tendo a participação, protagonismo e fortalecimento dos povos e organizações indígenas, portanto um projeto alinhado aos ideais de etnodesenvolvimento.

A implantação desse projeto no sul do país abarcou três aldeias indígenas sob responsabilidade de uma consultora do Projeto que teve como tarefa realizar levantamento de dados e estabelecer indicadores de sustentabilidade e identificar e articular atores para realizar o Projeto nas terras indígenas Ibirama (SC) dos povos indígenas Xokleng, Guarani e Kaingang, terra indígena Mangueirinha (PR) povo indígena Kaingang e terra indígena do Oco'y, povo indígena Avá-Guarani. Em vista disso, entende-se que se tratou de tarefa homérica visto que as respectivas áreas são constituídas de povos e contextos territoriais distintos.

O Projeto GATI no Oco'y buscou alcançar resultados que condiziam com as peculiaridades do local, isto é, projetou-se solucionar problemas de alimentação, produção orgânica e geração de renda. Entretanto, sua aplicação deixou a desejar, uma vez que sofreu descontinuidade em consideráveis períodos e não foi estabelecido um indivíduo, órgão ou instituição para dar ritmo às atividades.

Nos diálogos e entrevistas realizadas com diferentes indivíduos, foi possível constatar dois elementos relevantes. Primeiramente, sabe-se que o Projeto GATI ocorreu, de fato, que foi uma boa proposta e que há a percepção dos envolvidos de que o Projeto acabou em seu melhor momento.

Por outro lado, não se percebe por parte de nenhum dos entrevistados quem são os responsáveis pelo Projeto. Em outras palavras, os entrevistados identificam participantes, tanto indivíduos como instituições, mas não identificam os responsáveis pela implantação e eficiência do Projeto. Um possível nome para se indicar como encarregado do Projeto seria o da consultora do PNUD, Rosa Villanueva, porém esta ficou encarregada de realizar um projeto sem qualquer equipe técnica por parte do Projeto, ficando ao seu cargo descobrir potenciais parceiros para a execução das atividades. Dessa forma, acabou por ficar refém da existência e competência desses parceiros.

Em análise ao Relatório Final (VILLANUEVA, 2015b), a consultora coloca como elemento negativo para o desenvolvimento das atividades a dúvida quanto a responsabilidade pelas ações no Oco'y, se estas são da Itaipu ou da FUNAI. Embora exista o impasse jurídico por se tratar de uma terra indígena sobreposta à Área de Preservação Permanente do Lago de Itaipu, entendese que a responsabilidade de supervisão das ações é da FUNAl, uma vez que esta é o órgão indigenista oficial e responsável pela preservação dos bens materiais e imateriais dos territórios indígenas. Entretanto, a Coordenação Técnica Local de Guaíra, responsável pelo atendimento a TI Oco'y não possui condições materiais e de pessoal para ir além do atendimento básico às comunidades indígenas.

Embora a Itaipu realize assistência técnica e desenvolva projetos na comunidade como meio de compensar os prejuízos que causou à comunidade AváGuarani no passado e, também, utilize estas ações como estratégia de marketing, a empresa não é a responsável legal pelo atendimento aos indígenas. Por fim, a consultora entende que só foi possível realizar as ações do Projeto graças ao apoio e contratação dos técnicos da APROSMI, o que indica a necessidade de uma equipe técnica para apoiar o projeto em cada localidade.

Percebem-se a amplitude e o potencial do Projeto GATI desde o estabelecimento dos primeiros objetivos, estes que observavam a necessidade da proteção 
ambiental, a participação indígena e o conhecimento territorial como elementos essenciais para gestão de uma terra indígena. Entretanto, na prática foi realizada uma ação verticalizada, sem integração comunitária, sem participação indígena e somente com algumas ações pontuais, estas que embora significantes mostraram-se muito incipientes. Percebe-se que, como manifestação de uma ação política, o Projeto foi relevante, porém, pelo lado da transformação social, foi irrisório.

o Projeto GATI é um marco importante para se pensar a realização de projetos em terras indígenas, pois aponta para uma direção positiva do desenvolvimento sustentável de terras indígenas; além disso, já indica ferramentas, metodologias e caminhos a seguir. Ainda assim, é preciso que haja maior engajamento do poder público e das organizações indígenas, bem como a criação de mecanismos de financiamentos mais eficientes para concretizar as ações que devem ser implantadas a médio e longo prazo, pois é subjacente à ideia da sustentabilidade o perpetuamento das ações. 


\section{Referências}

BAVARESCO, A; MENEZES, M. (2014) Entendendo a PNGATI: Política Nacional de Gestão Territorial e Ambiental Indígenas. Brasília. GIZ/Projeto GATI/Funai.

CANDIOTTO, L. Z. P. (2004) Uma reflexão sobre ciência e conceitos: o território na Geografia. In: Território e desenvolvimento: diferentes abordagens. RIBAS, Alexandre Domingues; SPOSITO, E. S; SAQUET, M. A. (Orgs). Francisco Beltrão: Unioeste.

CANDIOTTO, L. Z. P; CARRIJO; B. R; OLIVEIRA, J. A. (2008) A Agroecologia e as Agroflorestas no contexto de uma Agricultura Sustentável. In: ALVES, A. F. CARRIJO, B. R; CANDIOTTO, L. Z. P (Orgs). Desenvolvimento territorial e agroecologia. Expressão Popular. 1 ed. São Paulo.

EHLERS, E. (1996) Agricultura sustentável: Origens e perspectivas de um novo paradigma. Livros da Terra. São Paulo. GARCIA, F.P.S. (2014) A Implantação da Política Nacional de Gestão Ambiental e Territorial de Terras Indígenas (PNGATI) em Mato Grosso, Brasil. Dissertação de Mestrado. Cáceres/MT. UNEMAT.

GESTÂO AMBIENTAL E TERRITORIAL DE TERRAS INDÍGENAS. Projeto GATI promove apoio a quintais agroflorestais e hortas agroecológicas na TI Ava-Guarani de Oco'y (PR). Disponível em: <http://cggamgati.funai.gov.br/index.php/ projeto-gati/noticias/projeto-gati-promove-apoio-quintais-agroflorestais-e-hortas-agroecologicas-na-ti-ava-guarani-deocoy-pr/> Acesso em: set. 2016.

GTZ - Deutsche Gesellschaft für Technische Zusammenarbeit. (2009) Gestão Ambiental e/ou Territorial de/em Terras Indígenas: Subsídios para a construção da Política Nacional de Gestão Ambiental em Terras Indígenas conforme Portaria Interministerial $n^{\circ} 276 / 2008$. Brasília.

GUIMARÃES V. M. B. (2014) Política nacional de gestão territorial e ambiental de terras indígenas (PNGATI): a busca pela autonomia ambiental e territorial das terras indígenas no Brasil. In: Revista Direito Ambiental e sociedade. v. 4, n. 1, p. 157-177.

GUIMARÃES, M. D. A. (2014) Desenvolvimento Rural: Territórios e Redes. Tese de Doutorado (Doutorado em Ciências Sociais). Rio de Janeiro.

INGLEZ DE SOUZA, C. (2012) Gestão Territorial: Conceitos fundamentais. In: INGLEZ DE SOUZA, C; ALMEIDA, F. Gestão territorial em terras indígenas no Brasil. Brasília. Ministério da Educação, Secretaria de Educação Continuada, Alfabetização, Diversidade e Inclusão. Unesco. Coleção educação para todos, v. 39. Série vias dos saberes. n. 6.

INGLEZ DE SOUZA, C. (2012) Gestão Territorial: Conceitos fundamentais. In: INGLEZ DE SOUZA, C; ALMEIDA, F. Gestão territorial em terras indígenas no Brasil. Brasília. Ministério da Educação, Secretaria de Educação Continuada, Alfabetização, Diversidade e Inclusão. Unesco. Coleção educação para todos, v. 39. Série vias dos saberes. n. 6.

LIMA, D; POZZOBON, J. (2005) Amazônia socioambiental. Sustentabilidade ecológica e diversidade social. In: Estudos Avançados. v.19. n 54. p. 45-76.

LONG. N. (2007) Sociologia del desarollo: una perspectiva centrada em el actor. Centro de Investigaciones y Estudios Superiores en Antropologia Social. El Colegio de San Luis.

PROJETO GATI. Disponível em:<http://www.funai.gov.br/index.php/projeto-gati>. Acesso em: Mar. 2017.

RAFFESTIN, C. (1993) Por uma geografia do poder. Tradução de Maria Cecília França. São Paulo. Ática.

REDE DE COOPERAÇÃO ALTERNATIVA. (2013) Gestão territorial e ambiental em terras indígenas na Amazônia brasileira: os percursos da Rede de Cooperação Alternativa. São Paulo.

SAQUET, M. A; SPOSITO, E. S. (2008) Território, Territorialidade e Desenvolvimento: diferentes perspectivas no nível internacional e no Brasil. In: ALVES, A. F. CARRIJO, B. R; CANDIOTTO, L. Z. P (Orgs). Desenvolvimento territorial e agroecologia. Expressão Popular. 1 ed. São Paulo.

VILLANUEVA, R. E. (2012a) Síntese da reunião de instalação do Conselho Regional do Núcleo Regional Sul do Projeto GATI.

(2012b) Parcerias, Subsídios e Diagnósticos das Áreas de Referência: Terras Indígenas Ibirama (SC), Mangueirinha e Ava-Guarani de Oco'y (PR).

. (2014a) Produto 02: relatório de acompanhamento da formação e intercâmbios e outras capacitações envolvendo as Áreas de Referência; avaliação dos resultados e apresentação dos desdobramentos e encaminhamentos necessários.

(2014b) Produto 3: Documento contendo: (1) relatório da execução dos projetos elaborados no âmbito do projeto GATI; (2) necessidade de ajustes e/ou atividades complementares tais como contratações de consultorias, capacitações, materiais/equipamentos específicos. 
(2015a) Produto 04: Documento contendo relatório de acompanhamento das oficinas de etnomapeamento (cartografia social). Mar. 2015a.

(2015b) Produto 06: Sistematização, síntese e avaliação dos resultados da consultoria e das ações do Projeto GATI no Núcleo Regional Mata Atlântica Sul: Terras Indígenas Ibirama - SC, Mangueirinha e Ava-Guarani de Oco'y - PR. Ago. 